\title{
Diaphragmatic hernia: a rare adverse event of colonoscopy
}

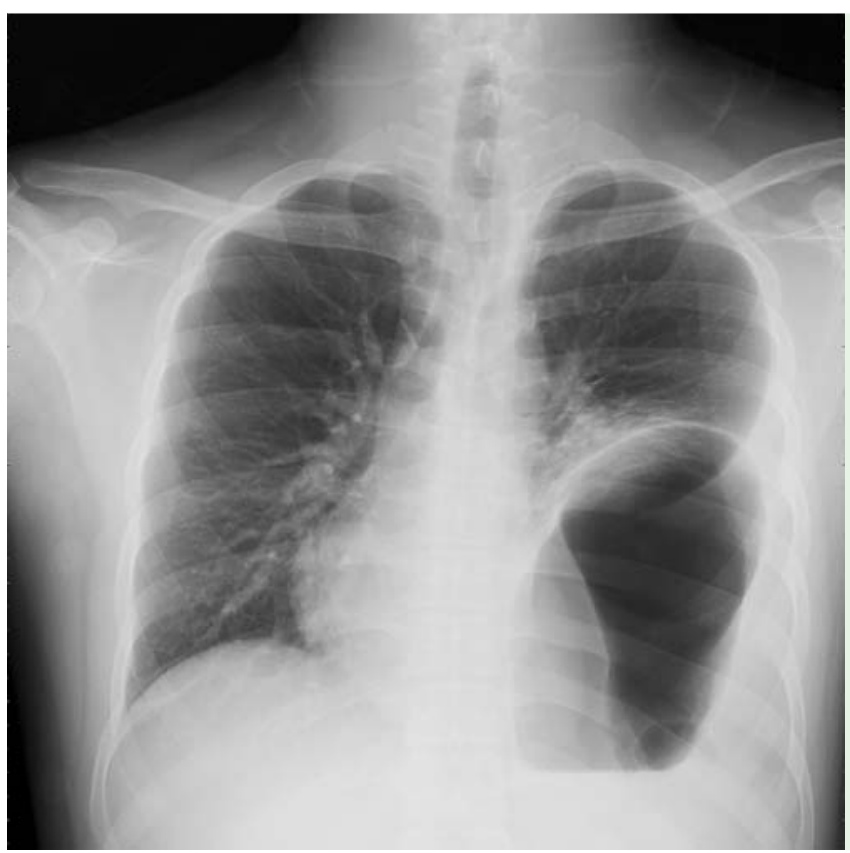

Fig. 1 Chest radiograph showed extensive herniation of the entire stomach and portions of the colon into the chest cavity.
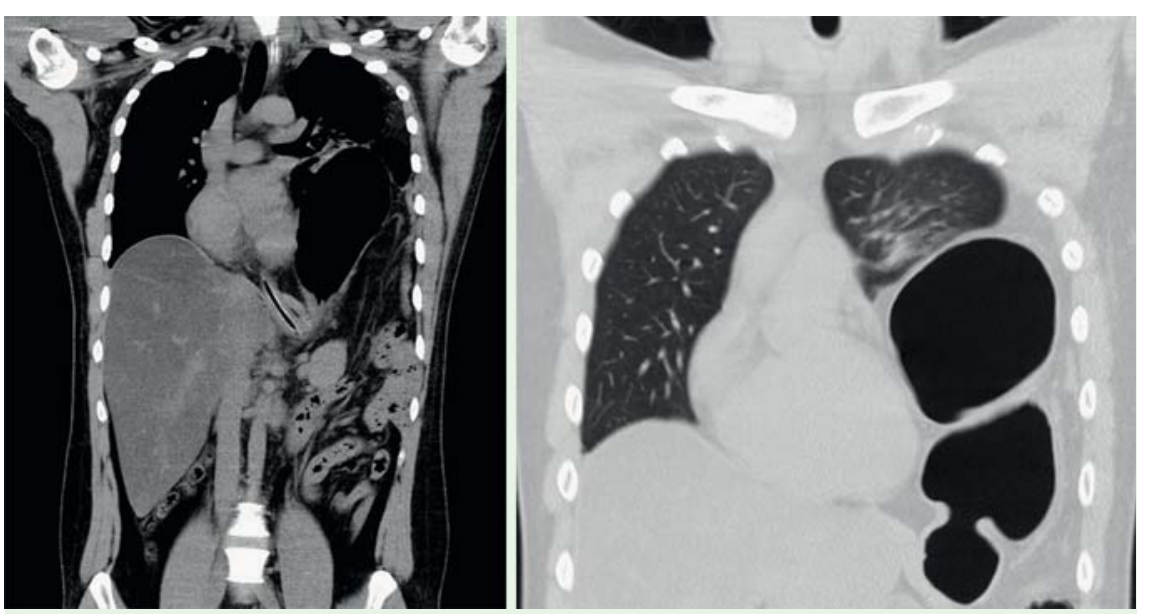

Fig. 2 Computed tomography scan of the lower chest showing herniation into the left chest.

A 25-year-old man underwent diagnostic colonoscopy because of mild upper abdominal pain. He had no history of trauma. The colonoscopy was completed without any significant difficulty. During the procedure, the patient did not complain of any pain or uncomfortable feelings. However, 24 hours after the procedure, the patient returned to the hospital with complaints of serious upper abdominal pain. On physical examination he had rebound tenderness in the upper abdomen and decreased breath sounds on the left chest. A chest radiograph ( $\bullet$ Fig. 1 ) indicated left diaphragmatic hernia. The chest and abdominal computed tomography (CT) scan ( $\bullet$ Fig. 2 ) confirmed a posterolateral diaphragmatic agenesis, with most of the stomach, the whole spleen, the tail of the pancreas, and the splenic flexure of the colon all appearing in the left chest. The patient underwent immediate left thoracotomy and diaphragmatic repair. He made an uneventful recovery and was discharged 15 days later. He is now asymptomatic.
Diaphragmatic hernias can be divided into two broad categories: congenital diaphragmatic defects and acquired diaphragmatic defects. Congenital diaphragmatic hernias occur through embryologic defects in the diaphragm with an incidence of $<1-5 / 10000$ births [1], and most patients present early in life rather than later. However, a subset of adults may present with a smaller congenital hernia that was undetected during childhood [2]. Acquired diaphragmatic hernia is commonly seen after trauma, especially traffic accidents [3].

Diaphragmatic hernia related to colonoscopy is a rare but usually life-threatening complication $[4,5]$. Only a few cases have been reported previously [4-8], and the incidence is not well defined at this time. However, laparotomy is usually required as soon as possible when the complication occurs.

Our endoscopic center performs 5000 6000 colonoscopies every year. To our knowledge, this is the first diagnosed case of diaphragmatic hernia as a consequence of colonoscopy.

Various risk factors should be considered in order to both decrease the risk and make an early diagnosis of diaphragmatic hernia. For patients who have a history of traffic accident, blunt trauma, and other diaphragmatic injuries, endoscopists should pay more attention to the possibility of this adverse event in patients undergoing colonoscopy. If necessary, an abdominal radiograph should be performed before the procedure. Moreover, increased abdominal pressure caused by air insufflation, and forceful and excessive advance during the colonoscopic procedure may push abdominal contents through a weakened diaphragm or an existing diaphragmatic defect. Chest and abdominal radiographs and $\mathrm{CT}$ are very helpful for the diagnosis of diaphragmatic hernia. Therefore, there should be a low threshold to perform them, especially for patients who have the risk factors described above.

In conclusion, diaphragmatic hernia caused by colonoscopy is a very rare adverse event, but the consequences are serious, with most patients requiring surgery. Therefore, it is very important for endoscopists to consider the possibility of herniation in patients undergoing colonoscopy.

Endoscopy_UCTN_Code_CPL_1AJ_2AB

Competing interests: None 


\section{Yongqiang Li, Qingning Li}

Department of Gastroenterology and Hepatology, Guangzhou First People's Hospital, Guangzhou, China

\section{References}

1 Gallot D, Boda C, Ughetto $S$ et al. Prenatal detection and outcome of congenital diaphragmatic hernia: a French registry-based study. Ultrasound Obstet Gynecol 2007; 29: 276 283

2 Elhalaby EA, Abo Sikeena MH. Delayed presentation of congenital diaphragmatic hernia. Pediatr Surg Int 2002; 18: 480-485

3 Meyers BF, McCabe CJ. Traumatic diaphragmatic hernia. Occult marker of serious injury. Ann Surg 1993; 218: 783 -790
4 Sodhi SS, Zech LAJr, Batura V et al. Diaphragmatic hernia with strangulated loop of bowel presenting after colonoscopy: case report. Int Arch Med 2009; 2: 38

5 Baumann UA, Mettler M. Diagnosis and hazards of unexpected diaphragmatic hernias during colonoscopy: report of two cases. Endoscopy 1999; 31: 274-276

6 Rustagi T. Intestinal obstruction from diaphragmatic hernia following colonoscopy. Am J Med Sci 2011; 341: 423-425

7 Koslowsky B, Adar T, Mahamid M et al. The unexpected twist in the plot: incarcerated diaphragmatic hernia complicating colonoscopy. Endoscopy 2013; 45 (Suppl. 02): E11

8 Alder AC, Scott DL, Browning JD. Colonoscopy: an unusual complication. Gastroenterology 2010; 138: 434,794

\section{Bibliography}

Dol http://dx.doi.org/ 10.1055/s-0033-1344866 Endoscopy 2013; 45: E400-E401

(c) Georg Thieme Verlag KG

Stuttgart · New York

ISSN 0013-726X

\section{Corresponding author}

Yongqiang Li, MD

Department of Gastroenterology and Hepatology Guangzhou First People's Hospital

Guangzhou 510180

China

Fax: +86-20-81048194

liyongqiang2000@gmail.com 